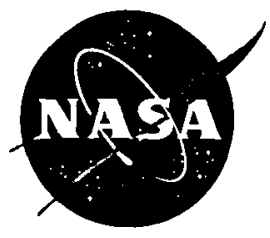

\title{
Estimation of Modal Parameters Using a Wavelet-Based Approach
}

\section{Sydney}

Rick Lind, Marty Brenner, and Haley

Dryden Flight Research Center

Edwards, California

\section{LIBRARY COPY}

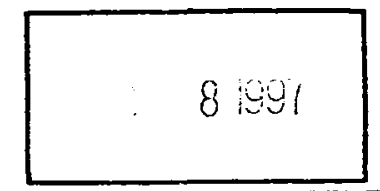

LANGLEY RESEARCH CENTER

LIBRARY NASA

HAMPTON, VIRGINIA 


\section{The NASA STI Program Office ... in Profile}

Since its founding, NASA has been dedicated to the advancement of aeronautics and space science. The NASA Scientific and Technical Information (STI) Program Office plays a key part in helping NASA maintain this important role.

The NASA STI Program Office is operated by Langley Research Center, the lead center for NASA's scientific and technical information. The NASA STI Program Office provides access to the NASA STI Database, the largest collection of aeronautical and space science STI in the world. The Program Office is also NASA's institutional mechanism for disseminating the results of its research and development activities. These results are published by NASA in the NASA STI Report Series, which includes the following report types:

- TECHNICAL PUBLICATION. Reports of completed research or a major significant phase of research that present the results of NASA programs and include extensive data or theoretical analysis. Includes compilations of significant scientific and technical data and information deemed to be of continuing reference value. NASA's counterpart of peer-reviewed formal professional papers but has less stringent limitations on manuscript length and extent of graphic presentations.

- TECHNICAL MEMORANDUM. Scientific and technical findings that are preliminary or of specialized interest, e.g., quick release reports, working papers, and bibliographies that contain minimal annotation. Does not contain extensive analysis.

- CONTRACTOR REPORT. Scientific and technical findings by NASA-sponsored contractors and grantees.
- CONFERENCE PUBLICATION. Collected papers from scientific and technical conferences, symposia, seminars, or other meetings sponsored or cosponsored by NASA.

- SPECIAL PUBLICATION. Scientific, technical, or historical information from NASA programs, projects, and mission, often concerned with subjects having substantial public interest.

- TECHNICAL TRANSLATION. Englishlanguage translations of foreign scientific and technical material pertinent to NASA's mission.

Specialized services that complement the STI Program Office's diverse offerings include creating custom thesauri, building customized databases, organizing and publishing research results ... even providing videos.

For more information about the NASA STI Program Office, see the following:

- Access the NASA STI Program Home Page at http://www.sti.nasa.gov

- $\quad$ E-mail your question via the Internet to help@sti.nasa.gov

- Fax your question to the NASA Access Help Desk at (301) 621-0134

- Telephone the NASA Access Help Desk at (301) 621-0390

- Write to:

NASA Access Help Desk NASA Center for AeroSpace Information 800 Elkridge Landing Road Linthicum Heights, MD 21090-2934 
National Aeronautics and

Space Administration

Dryden Flight Research Center

P.O. Box 273

Edwards, California 93523-0273

Reply to

Attn of: F-97-76-D-1048

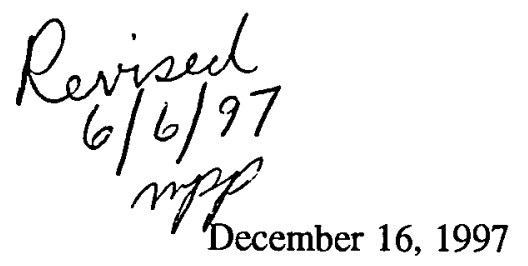

TO:

All Holders of NASA/TM-97-206300, Dated November 1997

FROM: $\quad$ F/Technical Publications Office

SUBJECT: Errata Sheet for NASA/TM-97-206300, Dated November 1997

NASA/TM-97-206300, Estimation of Modal Parameters Using a Wavelet-Based Approach, by Rick Lind, Marty Brenner, and Sydney M. Haley has an incorrect spelling on the cover page, title page, and report documentation page. Please make the following changes to this document.

1. Delete the first name spelled "Sidney" on all three pages of the document named above.

2. Insert the name "Sydney" on each of these pages.

Thank you for your cooperation.

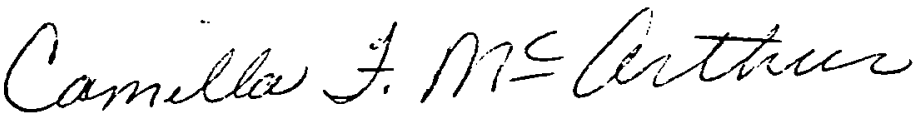

Camilla F. McArthur

Administrative Operations Specialist 


$$
\text { - }
$$


NASA/TM-97-206300

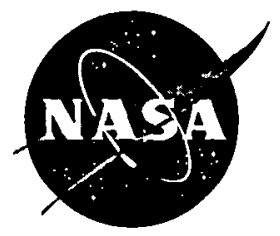

\title{
Estimation of Modal Parameters Using a Wavelet-Based Approach
}

\author{
Rick Lind, Marty Brenner, and \\ Dryden Flight Research Center \\ Edwards, California
}

National Aeronautics and

Space Administration

Dryden Flight Research Center

Edwards, California 93523-0273 


\section{NOTICE}

Use of trade names or names of manufacturers in this document does not constitute an official endorsement of such products or manufacturers, either expressed or implied, by the National Aeronautics and Space Administration.

Available from:

NASA Center for AeroSpace Information 800 Elkridge Landing Road Linthicum Heights, MD 21090-2934

Price Code: A16
National Technical Information Service 5285 Port Royal Road Springfield, VA 22161 Price Code: A16 


\title{
ESTIMATION OF MODAL PARAMETERS USING A WAVELET-BASED APPROACH
}

\author{
Rick Lind ${ }^{1} \quad$ Marty Brenner ${ }^{2} \quad$ Sydney M. Haley ${ }^{3}$ \\ NASA Dryden Flight Research Center, MS 4840D/RS, Edwards, CA 93523-0273
}

\begin{abstract}
Modal stability parameters are extracted directly from aeroservoelastic flight test data by decomposition of accelerometer response signals into time-frequency atoms. Logarithmic sweeps and sinusoidal pulses are used to generate DAST closed loop excitation data. Novel wavelets constructed to extract modal damping and frequency explicitly from the data are introduced. The socalled Haley and Laplace wavelets are used to track timevarying modal damping and frequency in a matching pursuit algorithm. Estimation of the trend to aeroservoelastic instability is demonstrated successfully from analysis of the DAST data.
\end{abstract}

\section{Nomenclature}

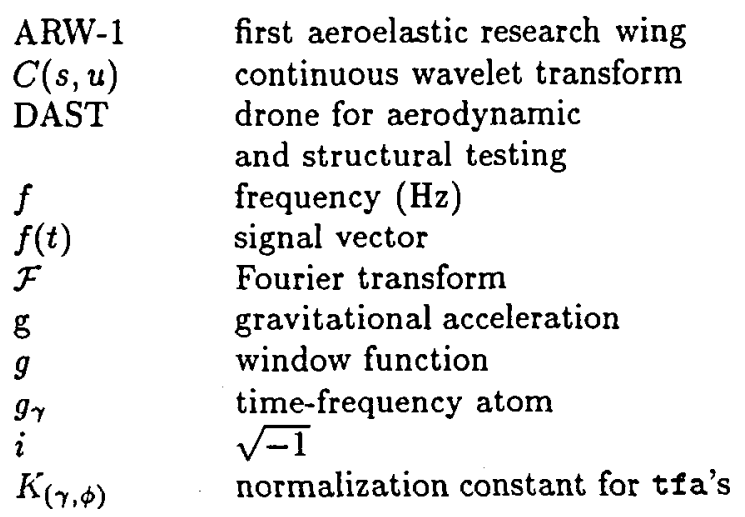

\footnotetext{
${ }^{1}$ NRC PostDoctoral Research Fellow, 805.258.3075, rick.lind@dfrc.nasa.gov, Member AIAA

${ }^{2}$ Flight Dynamics Engineer, 805.258.3793, martin.brenner@dfrc.nasa.gov, Member AIAA

${ }^{3}$ Cooperative Engineering Student, enrolled at University of Texas, Austin TX

${ }^{0}$ Copyright (C) 1997 by the American Institute of Aeronautics and Astronautics, Inc. No copyright is asserted in the United States under Title 17, U.S. Code. The U.S. Government has a royalty-free license to exercise all rights under the copyright claimed herein for government purposes. All other rights are reserved by the copyright owner.
}

$\begin{array}{ll}n y & \text { lateral acceleration } \\ n z & \text { normal acceleration } \\ R & \text { residual of projection in matching pursuit } \\ \operatorname{Re} & \text { real part } \\ s & \text { scale } \\ t f a & \text { time-frequency atom } \\ \text { sps } & \text { samples per second } \\ u & \text { time shift } \\ \text { Symbols } & \\ \gamma & \text { space of parameters }(s, \xi, u) \\ \gamma^{-} & \text {space of parameters }(s,-\xi, u) \\ \zeta & \text { damping ratio } \\ \xi & \text { modulation frequency of } t f a \\ \phi & \text { radian phase angle } \\ \Psi & \text { analyzing wavelet } \\ \omega & \text { radian frequency }\end{array}$

\section{Introduction}

Envelope expansion of new or modified aircraft often necessitates flight stability testing to verify safety margins to prevent against aeroservoelastic instability. Flight data is acquired for stability estimation and system identification to compare with analytical predictions as a function of flight parameters (Mach, dynamic pressure, $\alpha$ ). Any anomalies are regarded with care to guarantee safety of flight. Excitation systems are often essential to resolve stability trends from noisy measurements since atmospheric turbulence is generally insufficient to determine modal characteristics.

Time-frequency representations of time varying systems offer an alternative to traditional time and frequency domain stability tracking algorithms ${ }^{[2]}$. While damping estimates can be unreliable stability predictors ${ }^{[3]}$, damping and frequency trends are useful for noting changes in system dynamics as functions of flight condition. 
This paper introduces novel wavelets for modal time-frequency and time-damping estimation directly from the data, without use of intermediate model identification schemes. Stability parameters are extracted directly from the data by correlating properly designed wavelets with the system responses. Revisiting DAST ${ }^{[4]}$ ARW-1 (figure 1) (drone for aerodynamic and structural testing with the first aeroelastic research wing) data from flight testing performed in 1980, during which a catastrophic closed loop aeroservoelastic instability was encountered, modal frequency and damping are estimated as a function of time until instability. It is shown how wavelet processing can reliably identify time varying system stability trends.

\section{Stability Analysis using Time-Frequency Atoms}

\section{Basis Functions}

Fourier analysis maps a signal onto an amplitudefrequency plane by decomposing the signal into a weighted sum of infinite sinusoids. Its usefulness depends on properties of time invariance, linearity, and stationarity of the signal. Errors are also introduced from time truncation and windowing schemes. Signals that have time varying, transient, nonlinear, or nonstationary characteristics demand analysis functions which do not have the restrictions of Fourier methods.

Wavelets are basis functions of finite duration which decompose a signal into scaled and time-shifted versions of the analyzing function. The continuous wavelet transform is defined as ${ }^{[8]}$

$$
C(s, u)=\int_{-\infty}^{\infty} f(t) \Psi(s, u, t) d t
$$

where $u$ is the time translation, $s$ the scale, and $\Psi$ the analyzing wavelet. Gabor wavelets are Gaussianwindowed sinusoids (figure 2) described as

$$
\Psi(s, u, t)=e^{-\frac{1}{2}\left(\frac{t-\Sigma}{s}\right)^{2}} \cos (t)
$$

Conventional wavelet analyses map signals onto the scale-time or frequency-time plane since scale and frequency are inversely proportional to each other. This restriction inhibits the extraction of modal parameters from flight data. Hence, time-frequency atoms (tfa's) $)^{[5]}$ are introduced which are well localized in time, and frequency is independent of scale. The tfa's decompose a signal based on its local structure in terms of time, frequency, and scale independently. General families of tfa's are generated by scaling, translating, and modulating a window function $g(t)$ (see Appendix). Gabor wavelet window functions

$$
g\left(\frac{t-u}{s}\right)=e^{-\frac{1}{2}\left(\frac{t-z}{s}\right)^{2}}
$$

produce the following tfa's over the parameter space of $\gamma=(s, \xi, u)$ ( $\xi$ is frequency)

$$
g_{\gamma}(t)=\left(\pi s^{2}\right)^{-\frac{1}{4}} e^{-\frac{1}{2}\left(\frac{t-z}{\varphi}\right)^{2}} e^{j \xi t}
$$

The parameters $(s, u, \xi)$ are independently adjusted based on local signal properties.

A Haley wavelet is presented here as the doublesided exponentially damped sinusoid of figure $3 \mathrm{ex}$ pressed as

$$
\Psi(s, u, t)=e^{-\left|\frac{t-\varepsilon}{s}\right|} \cos (t)
$$

and generating the following tfa's over $\gamma=(s, \xi, u)$ (see Appendix),

$$
g_{\gamma}(t)=\frac{1}{\sqrt{s}} e^{-\left|\frac{t-x}{i}\right|} e^{j \xi t} .
$$

This wavelet is designed to independently extract modal damping and damped vibration frequency from a set of data, both as functions of time. Therefore, signals are mapped to the frequency-time and damping-time planes. Viscous damping ratio, $\zeta$, is estimated empirically by the following expression

$$
\zeta=\frac{10 \pi T}{s \xi}
$$

where $T$ is the sampling interval of the discrete time signal. Intuitively, as the scale, $s$, of the wavelet lengthens, damping ratio is reduced. For damping ratios typical of structural systems, parameter $\xi$ estimates $\omega_{n} \approx \omega_{d}$, or natural frequency $\omega_{n}$ as an equivalent approximation of damped frequency $\omega_{d}$.

Finally, a Laplace wavelet is introduced as a rightsided version of the Haley wavelet, or a representation of an impulse response (figure 4) and is expressed as

$$
\Psi(s, u, t)= \begin{cases}\sqrt{\frac{2}{3}} e^{-\left|\frac{t-u}{x}\right|} \cos (t) & t-u \geq 0 \\ 0 & t-u<0\end{cases}
$$




\section{Matching Pursuit}

The matching pursuit algorithm ${ }^{[5]}$ decomposes a signal into a linear expansion of tfa's that are from a redundant dictionary of functions. The wavelet bases are chosen according to desired features to be detected, or parameters to be extracted, from a signal. With a parametric dictionary of specific time-frequency atoms, matching pursuit will define an adaptive scale-frequency-time transform. The algorithm proceeds as follows (see Appendix):

1. Choose initial tfa corresponding to largest coefficient of $C(s, u)$ decomposition

2. Optimize over $\gamma=(s, \xi, u)$ by maximizing inner product of the signal with tfa dictionary

3. Extract optimal tfa from the signal

4. Repeat optimal extraction procedure until decomposition residual is below specified tolerance

Once the signal is decomposed to a desired degree, reconstruct a signal from the extracted dictionary elements. The energy distribution of the reconstructed signal in the frequency-time domain is generated using a Wigner distribution ${ }^{[5]}$.

\section{$\underline{\text { Simulation Tests }}$}

Results from the analysis of simulated data is presented to test the accuracy of the frequency and damping values from application of matching pursuits using the Haley and Laplace wavelets. Various types of simulated data are used in the tests. Haley decompositions are tested using the following signals of $100 \mathrm{sec}$ each:

1. One double-sided exponentially damped sinusoid

2. Three separated double-sided exponentially damped sinusoids

3. One double-sided exponentially damped sinusoid with $60 \%$ noise

4. Three separated double-sided exponentially damped sinusoids with $60 \%$ noise

Laplace decompositions are also tested using the above, replacing double-sided with single-sided sinusoids. From the results of table 1, the capability of these tra's to extract the true values is very encouraging. Values of estimated frequency and damping match the simulated 'true' values quite well. For clean data, the estimated values are essentially exact. Noisy data results introduce a variation in some estimates, but the true value is always in the range of variation.

\section{Analysis of DAST Data with Wavelets}

The objective of the NASA DAST program was to pursue investigations in transonic and supersonic regimes using a series of aeroelastic research wings on drones ${ }^{[6]}$. These drones were equipped with a flutter suppression system to enable flight beyond the open-loop stability boundary. Wingtip accelerometer response data at $500 \mathrm{sps}$ was acquired for logarithmic chirps and sinusoidal doublets of a single cycle $20 \mathrm{~Hz}$ sine wave into the aileron control surface.

This paper will present analysis of right wingtip accelerometer data in response to an aileron chirp input and a series of doublets just before the drone encountered an aeroservoelastic instability ${ }^{[4]}$ with the flutter suppression system engaged. Several types of wavelet tfa's are used in the analysis to process the short time data measurements of the transient modal responses. Each analysis (figures 5 through 8 ) produces plots of the original signal (a. top), the residual signal after the matching pursuit decompositionextraction procedure (b), reconstruction of the original signal from the decomposition (c), frequency estimates as a function of time (d), and damping estimates as a function of time, if applicable (e).

Gabor, Haley, and Laplace wavelets are utilized with the matching pursuit algorithm to extract modal natural frequencies from the flight data. Figure 5 presents an example of the information obtained from this procedure using a Gabor tfa. The top plot, figure $5 \mathrm{a}$, shows the original accelerometer response from the chirp input to the aileron. Figure $5 \mathrm{~b}$ presents the noise remaining in this signal after extracting the tfa's which result in the reconstructed signal of figure $5 \mathrm{c}$.

The bottom plot, figure $5 \mathrm{~d}$, presents the estimated values of the modal natural frequencies. Each circle on this plot indicates a frequency for which the wavelet had a high correlation with the measured data. Circles representing the highest energy extraction from the signal by the tfa correspond to modal 
responses. The increasing frequency as a function of time for the wavelet correlations agrees with the logarithmically increasing frequency in the chirp signal and demonstrates the additional time information that cannot be obtained from traditional Fourier analysis.

Modal frequencies similar to figure $5 \mathrm{~d}$ are computed using the Haley and Laplace wavelet tfa's. These frequencies agree closely with the Gabor wavelet analysis; however, the Haley and Laplace tfa's additionally extract modal damping. For this reason, the remaining discussion will consider only the Haley and Laplace wavelet analysis.

The matching pursuit algorithm is able to extract information about multiple modal responses by correlating wavelets of different frequency and damping (related to wavelet scale) with the measured data. Modal estimates are separated for clarity of presentation with figure 6d-e displaying the estimated Wing Torsion mode and figure $7 \mathrm{~d}-\mathrm{e}$ displaying the estimated Wing Bending modal estimates.

Frequency estimates of the Wing Torsion mode in figure $6 \mathrm{~d}$ remain nearly constant at $25.5 \mathrm{~Hz}$ throughout the data set. The damping value of $\zeta \approx 0.075$ also shows little variation throughout the series of doublets. These values agree with the results of previous post-flight estimates $[1,7]$.

The Wing Bending mode is of particular interest since this mode went unstable and resulted in the instability which destroyed the drone. The information obtained by the matching pursuit analysis with the Haley wavelet is given in figure 7 . The estimated natural frequency for this mode shows some variation at different test points throughout the data set but remains centered around $20 \mathrm{~Hz}$. Estimated damping, however, shows significant variation. The tfa analysis tracks modal damping decreasing steadily from $\zeta \approx 0.02$ to near zero after 40 seconds of data.

Similary, the Laplace tfa analysis given in figure 8 indicates the impending instability. The estimated damping in figure $8 \mathrm{e}$ shows the same decrease in damping from $\zeta \approx 0.02$ to near zero after 40 seconds of data.

The Haley and Laplace wavelet analysis agree with the true behaviour of the DAST drone. Each wavelet indicates the drone to be on the verge of instability for the Wing Bending mode after 40 seconds of data. In reality, this mode did go unstable inmediately after the 40 seconds during which this data set was recorded.

Algorithms are currently being developed which implement this matching pursuit strategy with reduced computational effort. The large amount of energy remaining in the signals after the correlated wavelets are extracted in figures $6 \mathrm{~b}, 7 \mathrm{~b}$, and $8 \mathrm{~b}$ is due to terminating the analysis before all the energy could be extracted by the wavelets. The process was stopped once the main features of the data were determined.

\section{Conclusions}

An aeroservoelastic system was used to test a method for time-frequency estimation of modal parameters using wavelets. Time-frequency-scale data processing allows improved visualization and understanding of the signal information content. Tuned basis functions for specific applications assist in identifying structure (shape, amplitude, frequency, duration, and timing of events) in the data.

Wavelets are exploited to parameterize the data such that stability trends can be detected accurately in a time-varying flight test scenario. In this appication, time-frequency atoms are used in a matching pursuit algorithm to extract modal frequency and damping as functions of time. DAST data of the final seconds before a closed loop instability are analyzed to validate this approach as a stability indicator and modal tracker. Future work will enhance this capability for application in an on-line test environment.

\section{$\underline{\text { Acknowledgement }}$}

The authors would like to thank Prof. Ronald E. Nelson from the Arkansas Tech University Engineering Department for his assistance under the NASA-ASEE Summer Faculty Fellowship and NASA/University Joint Venture (JOVE) programs.

\section{$\underline{\text { Appendix }}$}

\section{Time-frequency Atoms}


Time-frequency atoms are functions well localized in both time and frequency which can decompose signals adaptively according to particular signal structures. General families of time-frequency atoms can be generated by scaling, translating and modulating a window function $g(t) \in \mathbf{L}^{2}(\mathbf{R})$. Assume $g(t)$ is real, continuously differentiable, $\|g(t)\|=1$, $\int_{-\infty}^{\infty} g(t) \neq 0$, and $g(0) \neq 0$. For any scale $s>0$, frequency modulation $\xi$, and time translation $u$, denote $\gamma=(s, \xi, u) \in \Gamma=\mathbf{R}^{+} \times \mathbf{R}^{2}$ and define

$$
g_{\gamma}(t)=\frac{1}{\sqrt{s}} g\left(\frac{t-u}{s}\right) e^{i \xi t} .
$$

The factor $\frac{1}{\sqrt{3}}$ normalizes $\|g(t)\|=1$. Generally $g(t)$ is even, centered at $u$ with most of its energy concentrated near $u$, and determined by size proportional to $s$. The Fourier transform of $g(t)$ is

$$
\hat{g}_{\gamma}(\omega)=\sqrt{s} \hat{g}(s(\omega-\xi)) e^{-i(\omega-\xi) u}
$$

For even $g(t), \hat{g}(\omega)$ is even and centered at frequency $\omega=\xi$. Its energy is concentrated near center and modulation frequency $\xi$.

To analyze signal structures of varying sizes, it is necessary to use time-frequency atoms of different scales. A wavelet transform decomposes signals over different scales, but the resulting atoms are restricted by the relation $\xi \propto \frac{1}{3}$. For signals that include scaling and highly oscillatory structures, the appropriate constraints on the scale and modulation parameters of the time-frequency atoms $g_{\gamma}$ cannot be defined apriori. Hence, an adaptive selection of the elements of the dictionary $\mathcal{D}=\left(g_{\gamma_{n}}\right)_{\gamma \in \Gamma}$ is needed depending on the local properties of signal $f(t)$. Finite linear expansions of time-frequency atoms are dense in $L^{2}(\mathbf{R})$, so the dictionary $\mathcal{D}$ is complete.

\section{Matching Pursuit Algorithm}

To compute a linear expansion of a signal $f \in \mathbf{L}^{2}(\mathbf{R})$ from the set $\mathcal{D}$, successive approximations of $f$ are performed with orthogonal projections on the vectors in $\mathcal{D}$ to best match dominant patterns in the data. The following algorithm, called matching pursuit, performs the adaptive decomposition.

A signal vector $f$ can be decomposed into $(<,>$ denotes inner product)

$$
f=\left\langle f, g_{\gamma_{0}}>g_{\gamma_{0}}+R f\right.
$$

where $R f$ is the residual vector after projecting $f$ onto vector $g_{\gamma_{0}}$. Since $g_{\gamma_{o}}$ is orthogonal to $R f$,

$$
\|f\|^{2}=\left.\left|<f, g_{\gamma_{0}}\right\rangle\right|^{2}+\|R f\|^{2} .
$$

Minimize $\|R f\|$ by choosing $g_{\gamma_{0}} \in \mathcal{D}$ such that $\mid<$ $f, g_{\gamma_{0}}>\mid$ is maximum, or at least find a vector $g_{\gamma_{0}}$ that is sub-optimal in the sense that

$$
\left|<f, g_{\gamma_{0}}>\right| \geq \lambda \sup _{\gamma \in \Gamma} \mid<f, g_{\gamma}>1
$$

where $0 \leq \lambda \leq 1$ is an optimality parameter. Now, by induction, suppose $R^{0} f=f$ so at the $n^{\text {th }}$ step the residue $R^{n} f$ is matched

$$
\left|<R^{n} f, g_{\gamma_{n}}>\right| \geq \lambda \sup _{\gamma \in \Gamma} \mid<R^{n} f, g_{\gamma}>1 .
$$

Now decompose $R^{n} f$ into

$$
R^{n} f=<R^{n} f, g_{\gamma_{n}}>g_{\gamma_{n}}+R^{n+1} f
$$

defining the residue at step $n+1$. Since $R^{n+1} f$ is orthogonal to $g_{\gamma_{n}}$,

$$
\left\|R^{n} f\right\|^{2}=\left|<R^{n} f, g_{\gamma_{n}}>\right|^{2}+\left\|R^{n+1} f\right\|^{2} .
$$

and the decomposition up to the $m^{\text {th }}$ stage results in

$$
\begin{aligned}
f & =\sum_{n=0}^{m-1}\left(R^{n} f-R^{n+1} f\right)+R^{m} f \\
& =\sum_{n=0}^{m-1}<R^{n} f, g_{\gamma_{n}}>g_{\gamma_{n}}+R^{m} f .
\end{aligned}
$$

Therefore, the original signal $f$ is decomposed into a sum of the dictionary elements chosen to best match its residues. Although this decomposition is nonlinear, energy conservation is preserved since

$$
\|f\|^{2}=\sum_{n=0}^{m-1}\left|<R^{n} f, g_{\gamma_{n}}>\right|^{2}+\left\|R^{m} f\right\|^{2} .
$$

\section{Gabor Atoms}

The scale modulated form of the complex Gabor atom of equation 1 can be written $\left(\xi=2 \pi f_{c}\right.$, where $f_{c}$ is the center modulation frequency in Hertz)

$$
\begin{aligned}
g_{\gamma}(t) & =\frac{C_{o}}{\sqrt{s}} e^{-\frac{1}{2}\left(\frac{t-\alpha}{\cdot}\right)^{2}} e^{i \xi t} \\
g_{\gamma}-(t) & =\frac{C_{0}}{\sqrt{s}} e^{-\frac{1}{2}\left(\frac{t-u}{\cdot}\right)^{2}} e^{-i \xi t}
\end{aligned}
$$


where $\gamma=(s, \xi, u)$ and $\gamma^{-}=(s,-\xi, u)$, respectively. The $C_{o}$ to get $\left\|g_{\gamma}(t)\right\|=1$ is $C_{o}=\pi^{-\frac{1}{4}}$, so

$$
g_{\gamma}(t)=\left(\pi s^{2}\right)^{-\frac{1}{4}} e^{-\frac{1}{2}\left(\frac{t-x}{\gamma}\right)^{2}} e^{i \xi t} .
$$

When a signal $f(t)$ is real, dictionaries of real timefrequency atoms must be used to get a decomposition with real expansion coefficients. For any $\gamma=(s, \xi, u)$, with $\xi \neq 0$ and any phase $\phi \in[0,2 \pi)$, define

$$
g_{(\gamma, \phi)}=\frac{K_{(\gamma, \phi)}}{\sqrt{s}} g\left(\frac{t-u}{s}\right) \cos (\xi t+\phi) .
$$

The phase $\phi$ now appears explicitly rather than implicitly as in the complex representation of equation 1. It is the phase angle of the inner product $\left\langle R^{n} f, g_{\gamma}>\right.$ for each term of the decomposition. In the real Gabor case,

$$
g_{(\gamma, \phi)}=\frac{K_{(\gamma, \phi)}}{\sqrt{s}} e^{-\frac{1}{2}\left(\frac{t-\varkappa}{\epsilon}\right)^{2}} \cos (\xi t+\phi) .
$$

where real atoms are related to complex atoms by

$$
g_{(\gamma, \phi)}=\frac{K_{(\gamma, \phi)}}{2}\left(e^{i \phi} g_{\gamma}(t)+e^{-i \phi} g_{\gamma^{-}}(t)\right)
$$

Real matching pursuits are not equivalent to complex decompositions because $g_{\gamma}(t)$ and $g_{\gamma}-(t)$ are not orthogonal. The constant $K_{(\gamma, \phi)}$ to maintain $\left\|g_{(\gamma, \phi)}\right\|=1$ for real atomic decompositions becomes

$$
K_{(\gamma, \phi)}=\sqrt{\frac{2}{1+\operatorname{Re}\left(e^{i 2 \phi}<g_{\gamma}(t), g_{\gamma^{-}}(t)>\right)}}
$$

and for real Gabor atoms ${ }^{[5]}$

$$
K_{(\gamma, \phi)}=\sqrt{\frac{2}{1+\operatorname{Re}\left(e^{i 2(\phi+\xi u)} e^{-(s \xi)^{2}}\right)}} .
$$

\section{Haley Atoms}

In the so-called Haley atomic decomposition introduced in this paper, the window function is $g(t)=$ $C_{o} e^{-|t|}$, and $C_{o}=1$ to get $\left\|g_{\gamma}\right\|=1$, so that

$$
g_{\gamma}(t)=\frac{1}{\sqrt{s}} e^{-\left|\frac{t-x}{s}\right|} e^{i \xi t}
$$

Now equation 2 still holds, but the inner product is different. Specifically, by changing variables from $t$ to $-p$

$$
\begin{aligned}
\left\langle g_{\gamma}(t), g_{\gamma}-(t)\right\rangle & =\frac{1}{s} \int_{-\infty}^{\infty} e^{-2\left|\frac{t-u}{s}\right|} e^{i 2 \xi t} \mathrm{dt} \\
& =\left.\frac{1}{s} \int_{-\infty}^{\infty} e^{-2 \mid \frac{p+u}{s}}\right|^{-i 2 \xi p} \mathrm{dp}
\end{aligned}
$$

which is also $\frac{1}{3}$ multiplied by the Fourier transform of $e^{-\left.2\right|^{p+z} \mid}$ with $\omega$ replaced by $2 \xi$. Since $\mathcal{F}\left[e^{-2 t}\right]=$ $\frac{4}{4+\omega^{2}}$, from the Fourier scaling and time-shift properties,

$$
\begin{array}{ccc}
\mathcal{F}[x(a t)] & = & \frac{1}{a} X\left(\frac{L}{a}\right) \\
\mathcal{F}\left[e^{-2|!|}\right]=s\left[\frac{4}{4+(s \omega)^{2}}\right]=X(\omega)
\end{array}
$$

and

$$
\begin{aligned}
\mathcal{F}\left[x\left(t-t_{0}\right)\right] & =e^{-i 2 \pi f t_{0}} X(f) \\
& =e^{-i \omega t_{0}} X(f) \\
\mathcal{F}\left[e^{-2 \mid t \pm \varepsilon}\right] & =e^{i \omega u} X(\omega) \\
& =\frac{4 s e^{i \omega u}}{4+(s \omega)^{2}} .
\end{aligned}
$$

Multiplying this result by $\frac{1}{3}$ and replacing $\omega$ by $2 \xi$ yields

$$
\begin{aligned}
\left\langle g_{\gamma}(t), g_{\gamma}-(t)\right\rangle & =\frac{1}{s}\left[\frac{4 s e^{i 2 \xi u}}{4+4 \xi^{2} s^{2}}\right] \\
& =\frac{e^{i 2 \xi u}}{1+(s \xi)^{2}}
\end{aligned}
$$

for the expression in equation 2 . Hence, for the Haley atom,

$$
K_{(\gamma, \phi)}=\sqrt{\frac{2}{1+\operatorname{Re}\left(\frac{e^{i 2(\phi+\xi \psi)}}{1+(s \xi)^{2}}\right)}}
$$

\section{$\underline{\text { Laplace Atoms }}$}

Laplace atoms are a trivial modification of Haley atoms by a factor of $\frac{1}{2}$, resulting in $\frac{C_{0}^{2}}{2}=1$ to get $\left\|g_{\gamma}\right\|=1$, so that

$$
g_{\gamma}(t)=\sqrt{\frac{2}{s}} e^{-\left|\frac{t-x}{c}\right|} e^{i \xi t} .
$$

\section{References}

[1] Bennett, Robert M. and Irving Abel, "Application of a Flight Test and Data Analysis Technique to Flutter of a Drone Aircraft", AIAA Paper 810652, Atlanta, Ga. 
[2] Brenner, Martin J., Wavelet Analyses of $F / A$ 18 Aeroelastic and Aeroservoelastic Flight Test Dala, NASA TM-4793, April 1997.

[3] Brenner, Martin J., Richard C. Lind, and David F. Voracek, Overview of Recent Flight Flutter Testing Research at NASA Dryden, NASA TM4792, April 1997.

[4] Gilyard, Glenn B. and John W. Edwards, Real-time Flutter Analysis of an Active FlutterSuppression System on a Remotely Piloted Research Aircraft, NASA TM-84901, January 1983.

[5] Mallat, Stéphane and Zhifeng Zhang, "Matching Pursuit with Time-Frequency Dictionaries" IEEE Transactions on Signal Processing, Vol. 41, No. 12, Dec. 1993, pp. 3397-3415.

[6] Murrow, H.N. and C.V. Eckstrom, "Drones for Aerodynamic and Structural Testing (DAST) - A Status Report", AIAA Journal of Aircraft, vol 16, August 1979, pp 521-526.

[7] Newsom, Jerry R. and Anthony S. Potozky, "Comparison of Analysis and Flight Test Data for a Drone Aircraft with Active Flutter Suppression", AIAA Paper 81-0640, Atlanta, Ga.

[8] Strang, G. and Truong Nguyen, Wavelets and Filter Banks, Wellesley-Cambridge Press, 1996.

\begin{tabular}{|c|c|c|c|c|}
\hline Signal & 1 & 2 & $\mathbf{3}$ & 4 \\
\hline firve & 8 & $8,4,20$ & 8 & $8,4,20$ \\
\hline Girue & .05 & $.005, .0075, .00375$ & .005 & $.005, .0075, .0037$ \\
\hline \multicolumn{5}{|c|}{ Haley Wavelet Results } \\
\hline$f_{\text {est }}$ & 8 & $8,4,20$ & 8 & $8,1-4,20$ \\
\hline Sert & .05 & $.006, .008,004$ & .005 & $.005, .0075, .0037$ \\
\hline \multicolumn{5}{|c|}{ Laplace Wavelet Results } \\
\hline$f_{e n t}$ & 8 & $9-10,4-6,20$ & 8 & $8-10,4,20$ \\
\hline Sest & .05 & $.005, .0075, .00375$ & $.005-.2$ & $.005-.2, .0075, .003$ \\
\hline
\end{tabular}

Table 1: Results of Matching Pursuit Tests using Simulated Data - $f$ is frequency $(\mathrm{Hz}), \zeta$ is damping ratio

\begin{tabular}{|c|c|c|}
\hline Mode & Calculated & Measured \\
\hline \multicolumn{3}{|l|}{ Symmetric Mode } \\
\hline Wing $1^{\prime \prime}$ Bending & 9.1 & 9.6 \\
\hline Fuselage $1^{\prime \prime}$ Bending & 16.5 & 16.2 \\
\hline Wing Bending-torsion & 29.6 & 29.1 \\
\hline \multicolumn{3}{|l|}{ Antisymmetric Mode } \\
\hline Fuselage 1 "Bending & 12.3 & 13.5 \\
\hline Wing $1^{\prime \prime}$ Bending & 21.7 & 19.3 \\
\hline Stabilizer $1^{\text {"Bending }}$ & 30.0 & 27.0 \\
\hline
\end{tabular}

Table 2: DAST ARW-1 Calculated and GVT-measured Elastic Modal Frequencies $(\mathrm{Hz})$

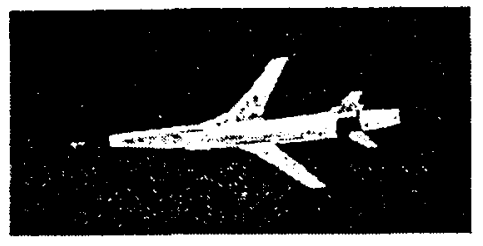

Figure 1: DAST ARW-1

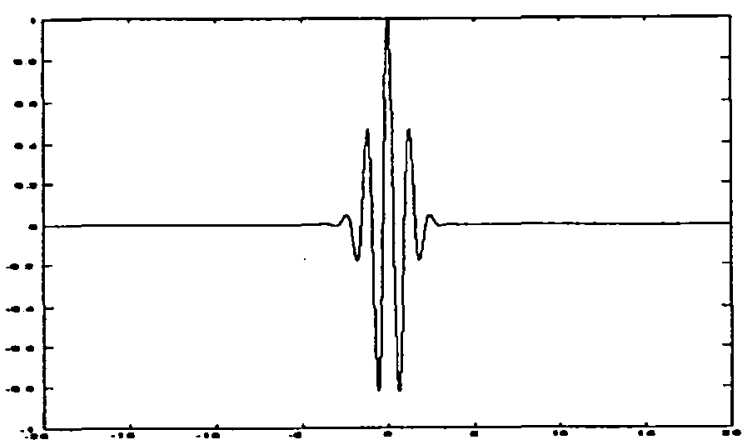

Figure 2: Gabor wavelet

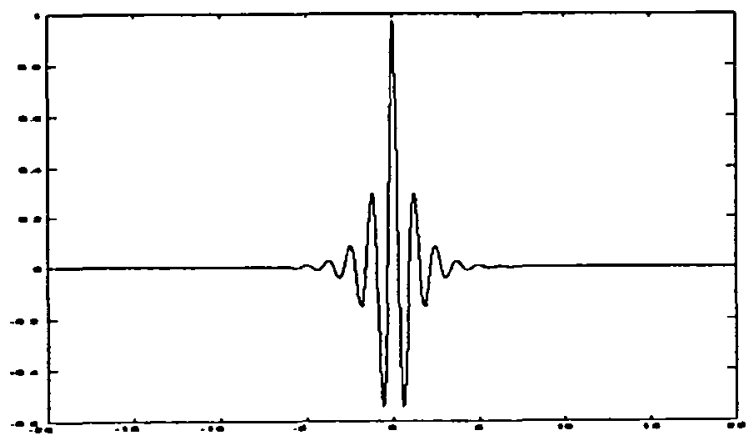

- Figure 3: Haley wavelet

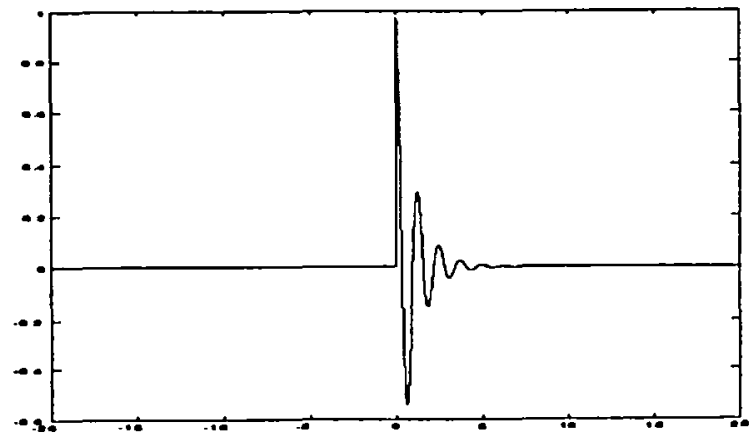

Figure 4: Laplace wavelet 

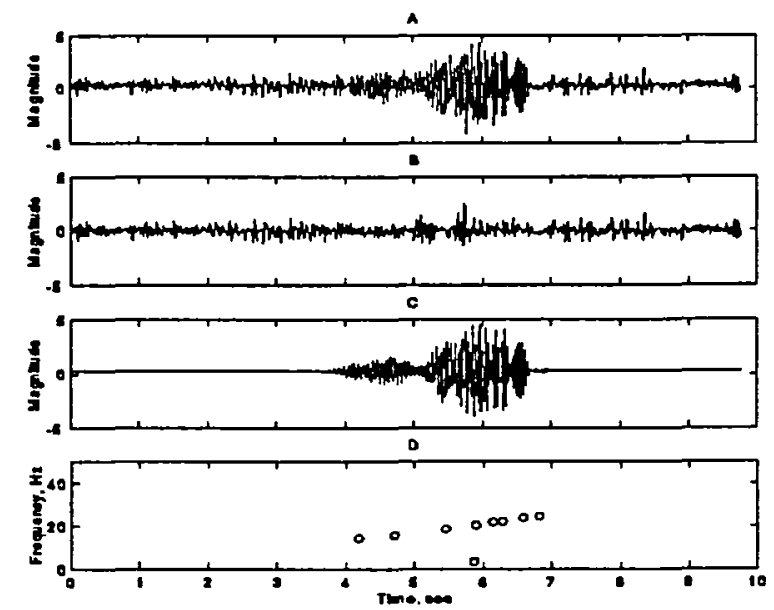

Figure 5: Gabor analysis of DAST chirp data
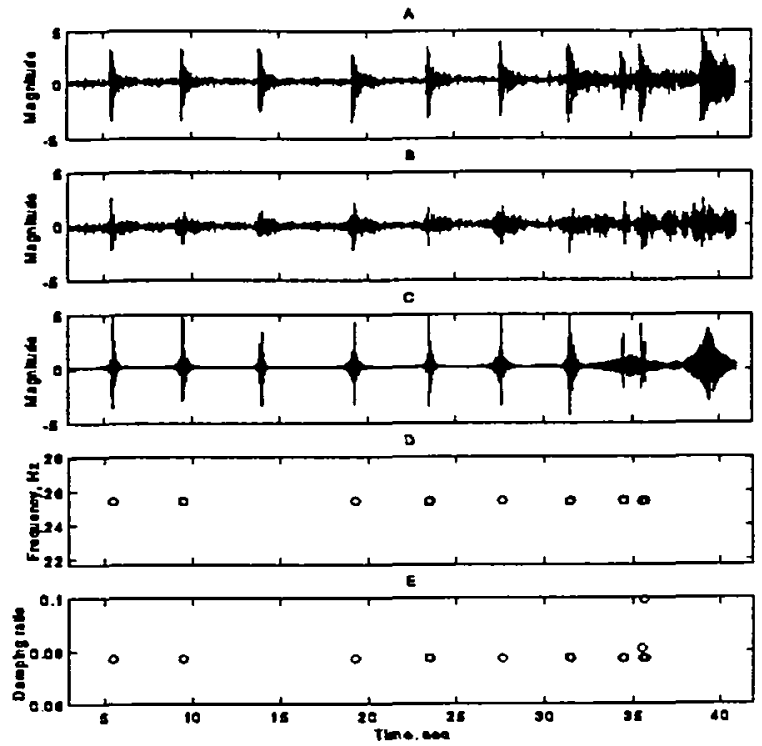

Figure 6: Haley analysis of DAST - Wing Torsion 

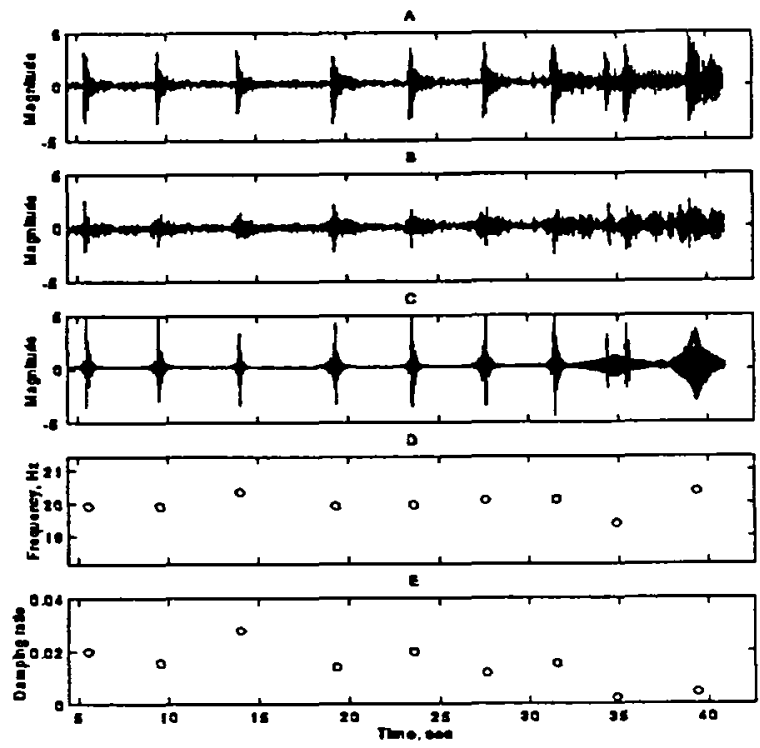

Figure 7: Haley analysis of DAST - Wing Bending
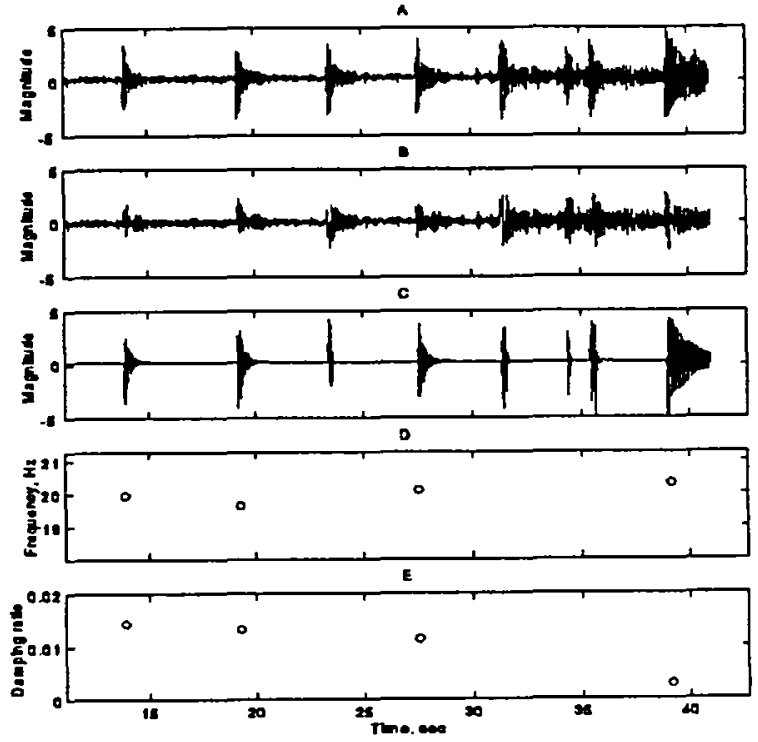

Figure 8: Laplace analysis of DAST - Wing Bending 


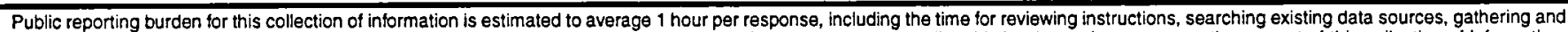

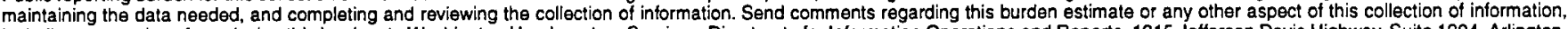

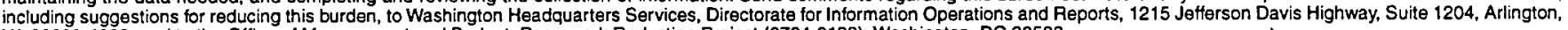
VA 22202-4302, and to the Office of Management and Budget, Paperwork Reduction Project (0704-0188), Washington, DC 20503.

\begin{tabular}{|l|l|l|l}
\hline 1. AGENCY USE ONLY (Leave blank) & $\begin{array}{l}\text { 2. REPORT DATE } \\
\text { November } 1997\end{array}$ & $\begin{array}{l}\text { 3. REPORT TYPE AND DATES COVERED } \\
\text { Technical Memorandum }\end{array}$ \\
\hline
\end{tabular}

4. TITLE AND SUBTITLE

Estimation of Modal Parameters Using a Wavelet-Based Approach

6. AUTHOR(S) Syelney

Rick Lind, Marty Brenner, and Sidney M. Haley

7. PERFORMING ORGANIZATION NAME(S) AND ADDRESS(ES)

NASA Dryden Flight Research Center

P.O. Box 273

Edwards, California 93523-0273

9. SPONSORING/MONITORING AGENCY NAME(S) AND ADDRESS(ES)

National Aeronautics and Space Administration

Washington, DC 20546-0001

\section{SUPPLEMENTARY NOTES}

Presented at AIAA Atmospheric Flight Mechanics Conference, New Orleans, Louisiana, August 8-11, 1997

12a. DISTRIBUTION/AVAILABILITY STATEMENT

12b. DISTRIBUTION CODE

Unclassified-Unlimited

Subject Category 08

13. ABSTRACT (Maximum 200 words)

Modal stability parameters are extracted directly from aeroservoelastic flight test data by decomposition of accelerometer response signals into time-frequency atoms. Logarithmic sweeps and sinusoidal pulses are used to generate DAST closed loop excitation data. Novel wavelets constructed to extract modal damping and frequency explicitly from the data are introduced. The so-called Haley and Laplace wavelets are used to track time-varying modal damping and frequency in a matching pursuit algorithm. Estimation of the trend to aeroservoelastic instability is demonstrated successfully from analysis of the DAST data.

\begin{tabular}{|c|c|c|}
\hline \multicolumn{3}{|l|}{ 14. SUBJECT TERMS } \\
\hline $\begin{array}{l}\text { 17. SECURITY CLASSIFICATION } \\
\text { OF REPORT }\end{array}$ & $\begin{array}{l}\text { 18. SECURITY CLASSIFICATION } \\
\text { OF THIS PAGE }\end{array}$ & $\begin{array}{l}\text { 19. SECURITY CLASSIFICATION } \\
\text { OF ABSTRACT }\end{array}$ \\
\hline Unclassified & Unclassified & Unclassified \\
\hline
\end{tabular}

15. NUMBER OF PAGES 15

16. PRICE CODE

$\mathrm{AO} 3$

20. LIMITATION OF ABSTRACT

Unlimited

Standard Form 298 (Rev. 2-89) Prescribed by ANSI Std. Z39-18 298-102 


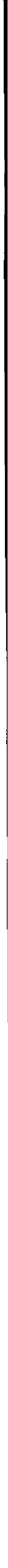


National Aeronautics and

Space Administration

Code JTT

SPECIAL FOURTH-CLASS RATE

POSTAGE AND FEES PAID

NASA

PERMIT No G27

Washington, D.C. 20546-0001

USA

Official Business

Penalty for Private Use, $\$ 300$

POSTMASTER: If Undeliverable (Section 158

Postal manual) Do Not Return 